Jurnal Sains Farmasi \& Klinis (p- ISSN: 2407-7062 | e-ISSN: 2442-5435)

diterbitkan oleh Ikatan Apoteker Indonesia - Sumatera Barat homepage: http://jsfkonline.org

\title{
Formulasi Tablet Lepas Lambat Natrium Diklofenak Menggunakan Pati Pisang Kepok (Musa balbisiana L) Sebagai Matriks
}

\section{(Formulations Slow Release Tablet Diclofenac Sodium Using Starch From Saba Banana (Musa balbisiana L))}

\author{
Deni Anggraini", Anita Lukman, Ria Mulyani \\ Sekolah Tinggi Ilmu Farmasi Riau, Pekanbaru, Riau, Indonesia
}

\begin{abstract}
Keywords:
Matrix, sustained release, starch, kepok banana

ABSTRACT: The formulation of slow release tablet of diclofenac sodium using a matrix of starch from saba banana and sodium carboxyl methyl cellulose as a comparison has been done. The purpose of this study was to determine whether the slow-release preparations produced with starch from saba banana met the requirements of slow-release tablet. The dissolution test results show the formula I (starch of saba banana) was dissolved $110.24 \%$, formula II ( sodium carboxyl methyl cellulose) was disolved $39.04 \%$ within 8 hours. The dissolution test results showed that starch of saba banana did not meet the requirements as a matrix because it could not not reduce the rate of dissolution. The kinetics of the release of active substances from the matrix between the two formulas followed Higuchi equation .

Kata Kunci:

Matriks, Lepas lambat, pati, pisang

ABSTRAK: Telah dilakukan formulasi tablet lepas lambat Natrium Diklofenak menggunakan matriks pati pisang kepok dan natrium karboksil metil selulosa sebagai pembandingnya. Tujuan penelitian ini untuk mengetahui apakah sediaan lepas lambat yang dibuat dengan matriks pati kepok pisang kepok memenuhi persyaratan tablet lepas lambat. Hasil uji disolusi menunjukan formula I (Pati Pisang Kepok) terdisolusi sebesar 110,24 \%, formula II (Natrium Karboksil Metil Selulosa) sebesar 39,04 \% dalam waktu 8 jam. Dari hasil uji disolusi menunjukan bahwa pati pisang kepok belum memenuhi persyaratan sebagai matriks karena belum dapat memperlambat laju disolusi. Kinetika pelepasan zat aktif dari matriks antara kedua formula mengikuti persamaan Higuchi.
\end{abstract}

\section{PENDAHULUAN}

Indonesia kaya akan sumber tanaman penghasil pati, tetapi pemanfaatannya sebagai eksipien dibidang farmasi masih sangat kurang. Pati merupakan karbohidrat yang tersebar dalam tanaman terutama tanaman berklorofil. Banyaknya kandungan pati pada tanaman tergantung asal pati tersebut. Pati umumnya hanya digunakan dalam sediaan padat seperti tablet sebagai pengisi, penghancur, dan pengikat $[1,2]$.

Pisang kepok mengandung karbohidrat yang cukup tinggi yaitu 70\%-80\% [3]. Pisang yang digunakan adalah pisang tua sebab kandungan patinya $21-25 \%$. Biasanya pisang yang dibuat pati adalah yang tidak tinggi kadar gulanya dan belum masak sehingga karbohidratnya tidak berupa gula sehingga cocok dibuat pati $[4,5]$.

Hasil penelitian terdahulu menunjukkan bahwa pati pisang kepok mengandung kadar amilopektin
*Corresponding Author: Deni Anggraini (Sekolah Tinggi Ilmu Farmasi Riau, Pekanbaru, Riau, Indonesia)

email: apt_deni@yahoo.com
Article History:

Received: 23 May 2016 Accepted: 03 Jun 2016

Published: 01 Nov 2016 Available online: 24 Des 2016 
yang tinggi yaitu 89,84\% [6]. Amilopektin ini berhubungan dengan daya pengembangan pati. karena pati tersebut di dalam air akan menyerap air dan membentuk gel [7] yang berfungsi sebagai barier penghambat pelepasan zat aktif. Dengan demikian pati pisang kepok diperkirakan dapat digunakan sebagai matriks dalam sediaan lepas lambat.

Sediaan lepas lambat merupakan sediaan yang dirancang untuk melepaskan obat ke dalam tubuh secara perlahan-lahan atau bertahap supaya pelepasannya lebih lama dan memperpanjang kerja obat [8]. Pembuatan suatu matriks dengan obat berada didalamnya atau tercampur homogen dengan bahan matriks merupakan salah satu cara yang dapat digunakan untuk membuat sediaan lepas lambat [9].

Berbagai macam matriks hidrofilik sintetik turunan selulosa diantaranya: Natrium Karboksimetilselulosa (NaCMC), polimetilmetakrilat dan bahan-bahan alam seperti xanthan gum, guargum, chitosan, telah banyak digunakan dalam berbagai penelitian. Dalam hal ini matriks hidrofilik akan mengembang (swelling) dan mengalami erosi, kedua proses ini akan mengontrol kecepatan pelepasan obat.

Natrium diklofenak merupakan suatu anti radang non steroid (Non steroid antiinflamatorydrugs, NSAID) yang merupakan suatu turunan asam fenil asetat. Natrium diklofenak digunakan pada pengobatan osteoarthritis dan rheumatoid arthritis. Obat-obat ini cepat diserap sesudah pemberian secara oral, tetapi bioavailabilitas sistemiknya antara 30-70 \%. Absorpsi Natrium diklofenak melalui saluran cerna berlangsung cepat dan lengkap, waktu paruh singkat yakni 1-3 jam [10]. Untuk mendapatkan konsentrasi efektif obat maka dapat dibuat dalam bentuk sediaan lepas lambat. Natrium diklofenak diserap secara cepat dan sempurna dalam lambung disamping itu sifat natrium diklofenak yang menunjang untuk dibuat sediaan lepas lambat yaitu waktu paruh di plasma pendek (1,5 jam), dan penggunaan dosis tidak terlalu besar sehingga cocok dibuat sediaan lepas lambat [11].

Berdasarkan uraian tersebut, maka dilakukan penelitian untuk memformulasi tablet lepas lambat natrium diklofenak menggunakanpati pisang kepok sebagai matriks dengan pembandingnya NaCMC. Tujuan penelitian ini untuk mengetahui apakah sediaan lepas lambat Natriun diklofenak yang dibuat dengan matriks pati pisang kepok memenuhi persyaratan dan mengetahui kinetika pelepasan zat aktif dari matriksnya.

\section{METODE PENELITIAN}

\section{Alat dan Bahan}

Alat yang digunakan adalah pisau, talenan, baskom, blender, kain flannel, oven, mortir, ayakan 80 mesh, timbangan, pipet tetes, beker gelas, magnetic stirrer, corong, kertas saring, stopwatch, spektrofotometer UV (Shimadzu), alat uji dissolusi, penangas air, oven (memmert), timbangan analitik, mesin cetak tablet Single punch, alat uji kekerasan (Stokes Monsato), desintegration tester, Roche friability tester, jangka sorong, bulk density tester, piknometer, ayakan mesh no 14 dan mesh no 16 serta alat-alat kaca yang biasa digunakan di laboratorium

Bahan-bahan yang digunakan untuk pengerjaan pembuatan pati pisang kepok dan pembuatan tablet lepas lampat natrium diklofenak adalah buah pisang kepok (Musa balbisiana), natrium diklofenak, air panas, aquadest, PVP, mg.stearat dan NaCMC.

\section{Isolasi Pati dari pisang kepok [12]}

Pisang kepok umur 80-90 hari atau $3 / 4$ penuh dikupas dan ditimbang sebanyak 2000 gram dan dipotong dalam bentuk balok segera direndam dalam air. Setelah itu pisang yang direndam tadi 
dihancurkan dengan blender menjadi bubur pisang. Untuk memudahkan penghancuran ditambahkan air dengan perbandingan pisang:air adalah 1:1. Selanjutnya bubur pisang diperas dengan kain saringan dan ampas nya ditambahkan air kembali lalu disaring dengan kain saringan. Filtrat yang diperoleh digabung dan dibiarkan mengendap selama 6-8 jam.

Selanjutnya pati hasil pengendapan dicuci dengan air 2-3 kali sampai dihasilkan pati yang berwarna putih (putih kekuningan). Pati pisang basah yang diperoleh dikeringkan dengan oven pda suhu $40^{\circ} \mathrm{C}$ selama 48 jam. Pati pisang yang telah kering dihaluskan dan diayak dengan ayakan 80mesh dan disimpan ditempat yang kedap untuk menghindari kerusakan. Didapatkan pati pisang kepok sebanyak 330 gram.

Formulasi Tablet Lepas Lambat Natrium Diklofenak

Tabel 1. Rancangan Formulasi tablet lepas lambat

\begin{tabular}{|c|c|c|}
\hline Bahan \% (b/b) & $F I$ & $F I I$ \\
\hline Natrium diklofenak & 12,5 & 12,5 \\
\hline PVP & 5 & 5 \\
\hline Pati pisang kepok & 80,5 & - \\
\hline $\mathrm{NaCMC}$ & - & 80,5 \\
\hline Mg. Stearat & 2 & 2 \\
\hline Total & 100 & 100 \\
\hline
\end{tabular}

Pembuatan masa granul dengan matriks pisang kepok

Tablet dibuat dengan metoda granulasi basah, dimana zat aktif (Natrium diklofenak) dan matriks (pati pisang kepok) dicampur. Lalu tambahkan bahan pengikat (PVP) sampai diperoleh massa lembab yang dapat dikepal. Massa lembab dilewatkan keayakan 12 mesh untuk membentuk granul. Granul yang terbentuk dikeringkan pada suhu $60^{\circ} \mathrm{C}$ selama 2 jam. Granul kering kemudian dilewatkan pada ayakan mesh 14 lalu dicampur dengan bahan pelincir (Mg Stearat) diaduk sampai homogen.

Pembuatan masa granul dengan matriks pembanding $\mathrm{NaCMC}$

Tablet dibuat dengan metoda granulasi basah, dimana zat aktif (Natrium diklofenak) dan matriks (NaCMC) dicampur. Lalu tambahkan bahan pengikat (PVP) sampai diperoleh massa lembab yang dapat dikepal. Massa lembab dilewatkan keayakan 12 mesh untuk membentuk granul. Granul yang terbentuk dikeringkan padatemperatur $60^{\circ} \mathrm{C}$ selama 2 jam. Granul kering kemudian dilewatkan pada ayakan mesh 14 lalu dicampur dengan bahan pelincir (mg. Stearat) diaduk sampai homogen. Masa granul yang didapat dilakukan evaluasi meliputi penentuan ukuran partikel, bj benar, bj nyata, bj mampat, kecepatan alir dan sudut diam, kandungan air, faktor hausner dan derajat kompresibilitas dan sudut diam, kandungan air, faktor hausner dan derajat kompresibilitas.

\section{Pencetakan tablet dan evaluasi}

Pencetakan dilakukan dengan mesin cetak single punch dengan mengatur bobot tablet 600 mg dan kekerasan sesuai yang diinginkan. Tablet yang dihasilkan dievaluasi meliputi :Keseragaman ukuran, keseragaman bobot, kekerasan, kerapuhan, waktu hancur dan uji disolusi.

\section{HASIL DAN DISKUSI}

Pada penelitian ini diformulasi tablet lepas lambat dengan menggunakan pati pisang kepok sebagai matriks. Pati pisang kepok memiliki kandungan amilopektin yang cukup tinggi $(89,84 \%)$ sehingga cukup potensial dijadikan matriks sediaan lepas lambat.

Tablet lepas lambat natrium diklofenak dibuat dengan bobot $600 \mathrm{mg}$ per tablet. Tablet yang telah dicetak dilakukan evaluasi tablet yang meliputi, 
yaitu keseragaman bobot, keseragaman ukuran, kekerasan, kerapuhan uji waktu hancur dan uji disolusi.

Keseragaman bobot merupakan salah satu parameter yang menentukan baik tidaknya produk tablet. Faktor yang menentukan yaitu sifat alir masa cetak. Masa cetak memiliki sifat alir yang baik. Hasil perhitungan keseragaman bobot tablet menunjukkan bahwa kedua formula memenuhi syarat yang ditetapkan farmakope Indonesia karena tidak lebih dari dua tablet yang bobotnya menyimpang $5 \%$ dan tidak ada satupun tablet yang bobotnya menyimpang 10\% dari bobot rata-rata. Berarti formula I dan II memenuhi persyaratan keseragaman bobot yang baik.

.Menurut Farmakope Indonesia Edisi III keseragaman ukuran yaitu kecuali dinyatakan lain, persyaratan diameter tablet tidak lebih dari $3 \mathrm{kali}$ dan tidak kurang dari 1 1/3 tebal tablet [13]. Dalam uji keseragaman ukuran dapat dilihat semua formula memenuhi syarat keseragaman ukuran.

Kekerasan tablet akan mempengaruhi waktu hancur Semakin keras tablet yang dihasilkan semakin lama waktu hancur. Pada penelitian ini United States Pharmacopeia (USP) menyatakan kekerasan tablet antara 4-8 kg/cm2. Dari hasil evaluasi kekerasan tablet didapatkan bahwa semua tablet memenuhi persyaratan dengan rata-rata kekerasan untuk formula I $(5,85)$ dan formula II $(5,6)$.

Evaluasi kerapuhan (friabilitas) berhubungan dengan kehilangan bobot akibat pecah/retak pada permukaan tablet. Semakin besar persentase kerapuhan, maka semakin besar massa tablet yang hilang. Persen kehilangan yang disyaratkan adalah $<1 \%$. Dari hasil formula I dan formula II diperoleh hasil yaitu $0,685 \%$ dan $0,943 \%$. Ini menunjukan bahwa hasil dari evaluasi kerapuhan dari kedua formula masih memenuhi persyaratan. Waktu hancur dilakukan untuk
menggambarkan lama tablet hancur dalam pencernaan. Waktu hancur tablet dipengaruhi oleh sifat fisik granul dan kekerasan tablet [14]. Pada formula I didapatkan waktu hancurnya dibawah 15 menit sedangkan untuk formula II waktu hancurnya mencapai 5 jam. Perbedaan ini karena formula I memiliki nilai porositas yang tinggi, selain itu juga formula I dengan matrik pati pisang kepok yang juga bersifat sebagai penghancur rmaka dapat menyebabkan waktu hancur tablet formula I sangat cepat sedangkan untuk. Formula II menggunakan NaCMC sebagai matrik sifat dari NaCMC yaitu pelepasan obatnya melalui proses erosi membentuk gel [15] sehingga cairan yang masuk ke pori-pori menjadi terhambat dan menyebabkan lamanya waktu hancur.

Selanjutnya dilakukan uji penetapan kadar zat aktif, syarat penetapan kadar zat aktif natrium diklofenak yaitu 90 - $110 \%$. Hasil yang didapat dari kedua formula masih memenuhi syarat karena masih masuk rangenya, yaitu pada formula I 90,42 \% dan formula II 96,90 \%. Tetapi pada formula I kehilangan kadar nya cukup tinggi, ini mungkin dipengaruhi pada saat pembuatan dari tablet saat pencetakan tablet dan homogenitas dari granul.

Disolusi adalah suatu proses zat padat masuk ke dalam pelarut sehingga terlarut [16]. Uji disolusi merupakan parameter penting untuk memberikan informasi dalam pengembangan bentuk sediaan yang mempunyai daya terapi yang optimal, uji disolusi dilakukan karena perlunya untuk menilai kecepatan penyerapan suatu tablet di dalam saluran pencernaan ataupun berkaitan dengan efek farmakologis zat aktif yang dikandung tablet [17].

Pada uji disolusi diharapkan zat aktif terlepas dari matriks sebesar 30\% dalam waktu 8 jam. Hasil uji disolusi tablet lepas lambat natrium diklofenak dalam medium dapar pH 6,8 menunjukkan perlambatan pelepasan zat aktif dari tablet, namun hasil pada formula I yang diperoleh tidak sesuai dengan kriteria yang diharapkan. Persen 


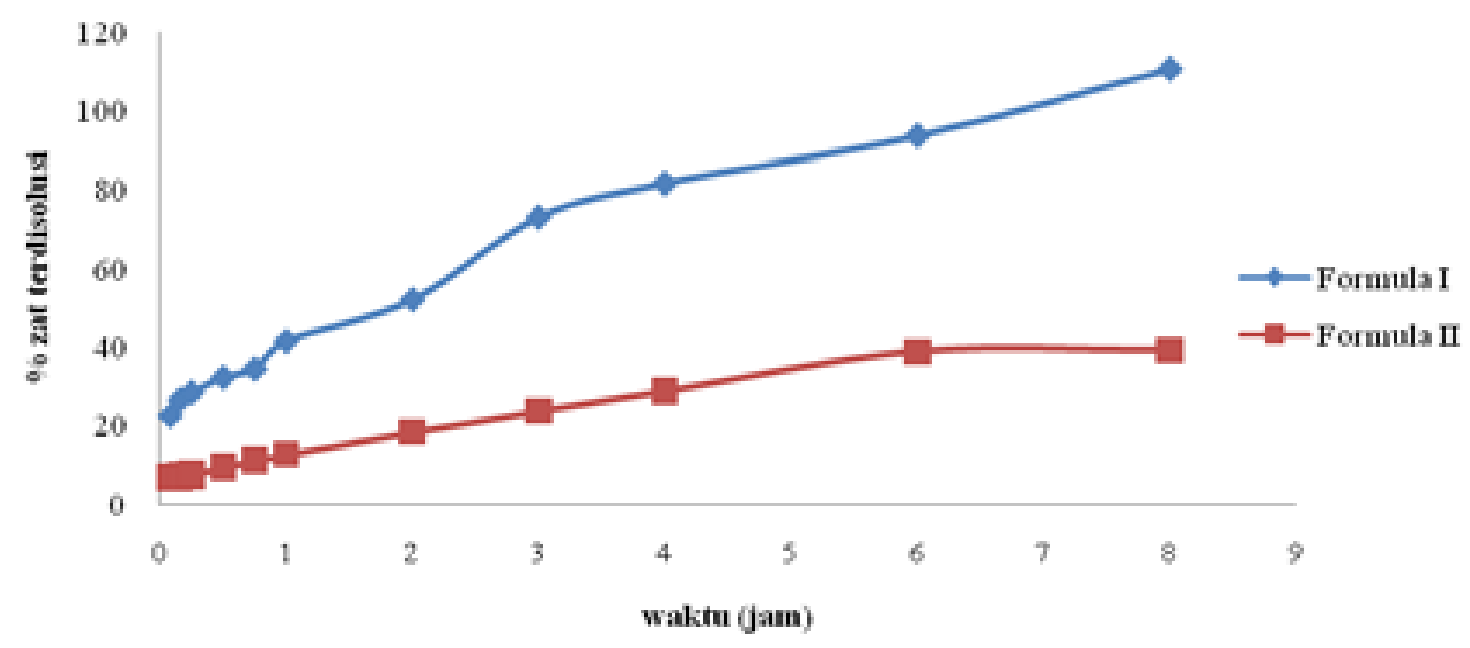

Gambar 1. Kurva disolusi tablet lepas lambat natrium diklofenak dalam medium dapar phosfat pH 6,8

zat terdisolusi selama 8 jam pada formula I mencapai $99,68 \%$, tetapi untuk formula II persen terdisolusinya selama 8 jam mencapai $37,80 \%$. Sehingga memberikan pelepasan obat lebih lama dari formula I. Hal ini kemungkinan terjadi karena adanya perbedaan matriks serta waktu hancur yang berbeda jauh dari kedua formula dan dipengaruhi juga karena porositas yang tinggi sehingga menyebabkan perbedaan pelepasan obat dari tablet.

Hasil dari uji disolusi kemudian dimasukkan kedalam model kinetika pelepasan obat seperti orde nol, orde satu, Higuchi dan Kosmeyer-Peppas sehingga dapat diketahui mekanisme pelepasan obat tersebut. Dari kedua formula yang diuji, formula I dan formula II menunjukkan pelepasan obat mengikuti persamaan Higuchi karena nilai r nya yang mendekati 1 dan didapatkan koefisien korelasi I 0,986 untuk formula I dan 0,975 untuk formula II

Kinetika Higuchi menjelaskan profil pelepasan obat tergantung akar waktu berdasarkan hukum Fick yang artinya kecepatan difusi lebih lambat dari pada kecepatan relaksasi dari matrik. Menurut Fick, laju disolusi senyawa padat ditentukan olehlaju disolusi suatu lapisan tipis dari larutan yang terbentuk disekeliling zat padat. Obatyang terlarut dalam larutan jenuh berdifusi kedalam pelarut dari daerah konsentrasi tinggi ke daerah dengan konsentrasi obat rendah [18].

\section{KESIMPULAN}

Pati pisang kepok masih belum memenuhi kriteria sebagai matriks tablet lepas lambat karena pelepasan obat nya belum sesuai yang diharapkan yaitu terdisolusi 30\% dalam waktu 8 jam. Kinetika pelepasan zat aktif natrium diklofenak formula I dan II mengikuti persamaan higuchi.

\section{DAFTAR PUSTAKA}

1. Cunningham, C.R. (1999). Maize starch and superdisintegrants in direct compression formulation. Pharm Manufac Rev, 12, 2224.

2. Winarno, F. G. (1989). Kimia Pangan dan Gizi. Gramedia Pustaka Utama, Jakarta.

3. Prabawati, S., Suyanti dan Setyabudi, A. D. (2008). Teknologi Pasca Panen dan Teknik Pengolahan Buah Pisang. Balai Besar Penelitian dan Pengembangan Pasca Panen Pertanian Badan Penelitian dan Pengembangan Pertanian.

4. Republika. (2005). Pisang buah kehidupan (online) http://www. republica.co.id.htm/ diakses 2 Februari 2007.

5. Republika. (2006). Pisang si kaya gizi dan khasiat (online) http:// www.republica.co.id.htm/ diakses 2 Februari 2007.

6. Junita, S. (2012). Isolasi Dan Uji Sifat Fisikokimia Pati Pisang Kepok ( Musa balbisiana). Skripsi. Sekolah Tinggi Ilmu Farmasi. Pekanbaru

7. Zobel HF, AM Stephen. (1995). Starch: Structure Analysis and Application, Marcel Dekker Inc, NewYork. 
8. Ansel, H, C. (1989). Pengantar Bentuk Sediaan Farmasi , Edisi IV. UI Press, Jakarta

9. Shargel, L., Susanna W, P., Andrew, B.C. (2005). Applied Biopharmaceutics \& Pharmacokinetics, $5^{\text {th }}$ edition, McGraw Hill, Singapore.

10. Ganiswara, G.S. (1995). Farmakologi dan Terapi. Edisi keempat. Jakarta. bagian Farmakologi Fakultas Kedokteran Universitas Indonesia.

11. Chuasuwan, B., Binjesoh, V., Polli, J. E., Zhang, H., Amidon, G. L., Junginger, H. E., ... \& Barends, D. M. (2009). Biowaiver monographs for immediate release solid oral dosage forms: Diclofenac sodium and diclofenac potassium. Journal of pharmaceutical sciences, 98(4), 1206-1219.

12. Susanti, L \& Sapitri R. I. (2008). Penggunaan Pati Pisang Sebagai Bahan Penghancur pada Pembuatan Tablet Antalgin. Jurnal Kimia dan Teknologi. Surakarta
13. Anonim. (1979). Farmakope Indonesia, Edisi III. Departemen Kesehatan Republik Indonesia, Jakarta

14. Banker, G.S. and Anderson, N.R. (1986). Tablets, in: Lachman, L. Lieberman, H.A., and Kanig, J.L.The Theory and Practise of Industrial Pharmacy, 3rdEdition, Marcel Dekker Inc., New York

15. Collet, J., and Moreton, C. (2002). Modified-release Peroral Dosage Form, dalam Aulton, M.E., Pharmaceutics: The Science Of Dosage Forms Design, Tablets, Edisi II, Churchill Livingstone, Edinburg-London-New York-Philadelphia-St Louis SydneyToronto, 289-305

16. Sulaiman, T.N.S. (2007). Teknologi dan Formulasi Sediaan Tablet, Yogyakarta: Pustaka Laboratorium Teknologi Farmasi Fakultas Farmasi UGM.

17. Siregar, Charles J.P. Prof. (2010). Teknologi Farmasi Sediaan Tablet, UI Press Jakarta

18. Abdou, HMJ. (1989). Dissolution Bioavailability and Bioequivalence. Pennsylvania: Mach Publishing Company 